\title{
IMPLEMENTAÇÃO ESTRATÉGICA NO GERENCIAMENTO DE PESSOAL: IMPORTÂNCIA NA VANTAGEM COMPETITIVA E GESTÃO DO CONHECIMENTO - UM ESTUDO DE CASO EM UMA EMPRESA DO RAMO DE AUTOPEÇAS
}

\section{IMPLEMENTING THE STRATEGIC MANAGEMENT OF PERSONAL AND COMPETITIVE ADVANTAGE IN THE IMPORTANCE OF KNOWLEDGE MANAGEMENT - A CASE STUDY IN A COMPANY'S AUTOMOTIVE INDUSTRY}

\author{
Geraldo Cardoso de Oliveira Neto ${ }^{1}$; Paulo José Gnidarxic ${ }^{2}$; Pedro Luiz de Oliveira Costa Neto \\ ${ }^{1}$ Universidade Nove de Julho - UNINOVE - São Paulo - Brasil \\ geraldo.neto@uninove.br \\ ${ }^{2}$ Universidade Nove de Julho - UNINOVE - São Paulo - Brasil \\ paulo.j@uninove.br \\ ${ }^{3}$ Universidade Paulista - UNIP - São Paulo - Brasil \\ politileia@uol.com.br
}

\begin{abstract}
Resumo
O propósito deste trabalho é apresentar um diferencial de competitividade com a implementação do gerenciamento de pessoal voltada para a disseminação do conhecimento. A metodologia da pesquisa é de origem exploratória, caracterizada pela maneira qualitativa e quantitativa por meio do método de pesquisa-ação. Para tanto, será apresentado um estudo de caso aplicado em uma empresa de autopeças no qual o problema consistia em pesquisar as causa para a não qualidade, o que levou à verificação da influência do conhecimento na qualidade dos produtos. A pesquisa trás informações sobre: liderança coletiva para gestão do conhecimento destacado a importância do líder como um conjunto mais rico e diverso com habilidades para disseminar o conhecimento entre os liderados, aprendizagem organizacional e vantagem competitiva, gestão do conhecimento como um fator determinante para adquirir, gerar, organizar, armazenar e disseminar o conhecimento. $O$ estudo tem por objetivo avaliar por meio de indicadores: $i$. o levantamento das falhas por motivo de falta de conhecimento, ii. se houve evolução do aprendizado após a implementação de treinamentos específicos, iii. o indice de PPM (peças por milhão), iv. a produtividade após melhorias na qualidade e conhecimento no que tange redução de retrabalho e aumento do faturamento. Chega-se a conclusão que a implantação estratégica no gerenciamento de pessoal voltada para disseminação do conhecimento pode modificar outros indicadores de desempenho da organização e a capacidade de aprender mais rapidamente do que os concorrentes como a principal vantagem competitiva no momento de tantas incertezas econômicas.
\end{abstract}

Palavras-chave: liderança coletiva; estratégia no gerenciamento de pessoal; gestão do conhecimento.

\section{Introdução}

A evolução dos sistemas de gestão das empresas vem se estruturando em função de 
necessidades da própria dinâmica em que se constitui o mundo moderno. Relacionamento entre países, mobilidade para pessoas, comunicação em tempo real, tecnologias de produção e controle, oferta de produtos maior que a demanda, abertura de mercados e acirrada competição promovem permanentes alterações nas estruturas e gestão para que a empresa possa se manter diante da concorrência. Nessa turbulência de panoramas é fundamental que as mudanças se dêem de forma segura para que tragam os benefícios que as motivaram. Muitas vezes é esquecido que o principal agente da mudança em uma organização é o fator humano detentor do conhecimento, que, com facilidade adapta-se constantemente a evolução dos novos sistemas de gestão.

Após a abertura de mercado, ocorreram muitas crises no mundo dos negócios, se torna imprescindível à implantação de estratégicas que contemplem o gerenciamento de pessoas e seus respectivos conhecimentos, pois estes fatores são primordiais para garantir a competitividade e sobrevivência das organizações. Segundo Albuquerque (1987); Anthony, Perrewé e Kacmar (1996); Ulric (1998) a abordagem estratégica de recursos humanos surgiu na década de oitenta, ressaltando o papel do RH (Recursos Humanos) na estratégia da empresa, e colocando enfase primordialmente, no alinhamento entre gestão de pessoas e estratégia organizacional e entre as estratégias, políticas e práticas de recursos humanos. Segundo Scharmer (2009) "qualquer que seja áreas que analisemos, da educação ao desenvolvimento sustentável, encontramos o mesmo desafio de liderança coletiva". "Entende-se como administração estratégia de recursos humanos a gestão que privilegia como objetivo fundamental, através de suas intervenções, a otimização dos resultados finais da empresa e da qualidade dos talentos que a compõem".

O alinhamento estratágico e a gestão de pessoas destacam-se como a abertura de mercado, as organizações trocam tecnologias e novos processos, e estes migram de suas filiais instaladas no exterior permitindo a igualdade entre as empresas quando comparamos fatores materiais portanto, na análise da estratégia a ser adotada surge o ponto diferencial que são as pessoas. O conhecimento tácito e explícito dos calaboradores e de seus líderes podem fazer a diferenças perante aos concorrentes e a base desta estratégia esta em fatores: a gestão conhecimento e a forma de como menssura-la através de um dos principais indicadores de qualidade que é a redução dos desperdícios.

Portanto objetivo deste artigo é evidenciar um diferencial de competitividade com a implementação do gerenciamento de pessoal voltada para a disseminação do conhecimento proporcionando a melhoria na qualidade dos produtos e serviços através da gestão doconhecimento.

Em específico objetiva-se:

a) Conhecer a nova forma de liderança em momento de crise;

b) Apresentar um exemplo de aplicação em uma empresa de autopeças que implementou a estratégia de pessoal voltada para disseminação do conhecimento em cinco passos; 
c) Mostrar por meio de indicadores de desempenho: i. o levantamento das falhas por motivo de falta de conhecimento; ii. A evolução do aprendizado; iii. o indicador de qualidade PPM (partes por milhão) e iv. a produtividade após melhorias na qualidade.

\section{Referências teóricas}

\subsection{A liderança coletiva}

$\mathrm{Na}$ atualidade o ritmo da mudança tem se acelerado tão rapidamente que o tamanho da empresa não é mais uma proteção. Companhias multibilionárias geralmente vêem suas posições competitivas erodir em meses. Sendo assim é necessário uma liderança coletiva, precisa-se de lideres com um conjunto mais rico e diverso de habilidades para disseminar o conhecimento entre os liderados, caiu o cartaz do autoritário, do comandante, que cedeu espaço para o desbravador da inteligência emocional e social, principalmente com consciência interpessoal.

Segundo França (2006) o líder precisa criar um clima participativo caracterizado pela rede interativa e horizontalizada de distribuição e troca entre os membros, com objetivos comuns, conduzindo o grupo para a solução de problemas principalmente em momento de crise. A liderança coletiva bem sucedida é aquela que desenvolve sistemas para criar uma organização que domina uma profunda fidelidade de seus funcionários e dos outros que interagem com a empresa, como consumidores e fornecedores (RAO, 2009).

Coletivamente criamos uma situação que gera resultados que ninguém deseja e, entretanto, nenhum dos líderes participantes se sente capaz ou se anima a modificar essa situação. Esse é um desafio da liderança coletiva que enfrentamos em relação à crise da economia financeira (SHARMER, 2009).

Sharmer (2009) complementa que na atualidade não adianta os gestores perseguirem os objetivos individuais e sim é necessário otimizar o conjunto, ter consciência da situação como um todo. Goleman (2009) chama a atenção sobre a necessidade dos lideres empresariais terem equilíbrio em momento de crise, e assevera a necessidade de utilizar a inteligência interpessoal muito maior na era da transparência corporativa atual que precisa valorizar os funcionários através da empatia e inteligência emocional.

Sharmer (2009) apresenta sete capacidades de liderança da teoria U e Rao (2009) mostra também, sete tarefas que estão diante do líder coletivo bem-sucedido. Portanto fundamentado em Sharmer; Rao (2009) será apresentado uma relação de quatorze pontos importantes (Quadro 1) que justificam a necessidade dos gestores em adquirir conhecimento sobre a liderança coletiva para a disseminação do conhecimento. Através dos quatorze pontos buscar-se-à a intensificação dessa ferramenta intelectual para a sobrevivência em momentos de crise. 
Quadro 1 - Relação entre as capacidades de liderança e as tarefas para o líder bem sucedido para sobreviver na crise

\begin{tabular}{|l|l|}
\hline \multicolumn{1}{|c|}{ Sharmer - capacidades de liderança da teoria U } & \multicolumn{1}{c|}{ Rao - tarefas para o líder bem-sucedido } \\
\hline $\begin{array}{l}\text { 1 - Ligar-se ao que está a sua volta: ouvir o que a vida o } \\
\text { chama para fazer. }\end{array}$ & $\begin{array}{l}8 \text { - Estabelecer uma missão estratégica inspiradora } \\
\text { focada em garantir a satisfação dos funcionários. }\end{array}$ \\
\hline $\begin{array}{l}2 \text { - Observar: comparecer aos lugares com sua mente } \\
\text { bem aberta. }\end{array}$ & $\begin{array}{l}9 \text { - Eliminar "desmotivadores" e obstáculos dos seus } \\
\text { subordinados, tornando o ambiente motivador. }\end{array}$ \\
\hline 3 - Sentir: conectar-se ao seu coração. & $\begin{array}{l}10-\text { Ser útil, não prepotente a fim de procurar formas de } \\
\text { ajudar todos os colaboradores a se realizar } \\
\text { profissionalmente e pessoalmente }\end{array}$ \\
\hline $\begin{array}{l}11-\text { Perseguir lucros depois da missão, porque o lucro é a } \\
\text { profunda de seu "eu" e de sua vontade. } \\
\text { conseqüência do sucesso. }\end{array}$ \\
\hline - Cristalizar: acessar o poder da intenção. & $\begin{array}{l}12 \text { - Remunerar com justiça } \\
13 \text { - Demonstrar compromisso com todos os envolvidos } \\
\text { buscando sempre integração, se precisar participar do } \\
\text { sofrimento dos membros, valorizar a diversidade e } \\
\text { impulsionar trabalhos em grupos. }\end{array}$ \\
\hline 7 - Desempenhar: tocar o grande violino. & $\begin{array}{l}14-\text { Estabelecer um compromisso com o aprendizado e a } \\
\text { justiça sentidos e pronunciados pelos colaboradores. }\end{array}$ \\
\hline
\end{tabular}

Fonte: Autores (2011)

Portanto a nova retórica empresarial para a sobrevivência em tempos de crise, exige principalmente que os gestores sejam líderes coletivos, isto é, germine uma profunda fidelidade de seus funcionários e dos outros que interagem com a empresa, como consumidores e fornecedores. Por meio dessa prática se torna possível eliminar objetivos individuais e almejar resultados conjuntos. Desta forma torna-se necessária a organização implementar estrategicamente o gerenciamento de pessoal para a disseminação do conhecimento.

No próximo tópico será apresentada em um primeiro momento a formulação estratégica para o gerenciamento de pessoal e em segundo, um modelo estratégico para o gerenciamento de pessoal. Com isso, busca-se orientar os gestores à intensificar a necessidade do planejamento estratégico no departamento de recursos humanos.

\subsection{Alinhamento estratégico do gerenciamento de pessoal para a gestão do conhecimento}

Neste tópico será apresentado um alinhamento estratégico na área de recursos humanos para a finalidade de valorizar e disseminar o conhecimento empresarial e consecutivamente melhorar a lucratividade da empresa. Segundo Certo e Peter (2005) a administração estratégica é definida como um processo contínuo e interativo que visa manter uma organização como um conjunto apropriado integrado a seu ambiente.

Boog (2002) relata que é necessário alinhar e implementar estratégias de pessoas, porque são importantes para canalizar e integrar as estratégias às competências requeridas pelo negócio, alavancando resultados mensuráveis e garantindo uma gestão eficaz de pessoas.

É importante se atentar como foco exclusivo deste artigo a valorização dos colaboradores na gestão do conhecimento e na competitividade da empresa, para isso, é necessário "planejar estratégias no gerenciamento de pessoas para a disseminação do conhecimento voltados ao aspecto 
sociotécnico", principalmente pelas mudanças constantes que ocorrem nas organizações.

Larson e Strehle (2002) relatam que os sistemas sociotécnicos são compostos de três elementos. Primeiro, o componente humano lida competências pessoais, definida em termos de conhecimento, habilidades, motivação e valores. Segundo, o componente organizacional inclui estratégia de recursos humanos na estrutura organizacional que corresponde a sistemas de tomadas de decisão, sistemas de recompensa, sistemas de treinamento, cultura e liderança, entre outros elementos. Por fim, a tecnologia refere-se a infra-estrutura disponível para a desenvolver a gestão do conhecimento capacitando os colaboradores a novos conhecimentos e tornando-os disseminadores de conhecimentos no ambiente que estão inseridos.

Os gerentes de pessoas precisam estar conscientes de que a extensão, a profundidade e escopo do conhecimento e das habilidades da empresa impulsionam, crescentemente, suas chances competitivas.

$\mathrm{Na}$ atualidade as possibilidades e restrições estratégicas já não estão baseadas na limitação do capital, na demanda, na capacidade de produção ou no acesso de mercados estrangeiros.

As restrições comerciais atuais são derivadas, principalmente da escassez de pessoas disponíveis qualificadas para exercer funções específicas, principalmente em encontrar competências gerenciais adequadas à mudanças constantes que ocorrem na economia globalizada.

$\mathrm{Na}$ atualidade os gerentes de pessoas precisam construir e disseminar novas formas de pensar e atuar no âmbito operacional e relacional entre os colaboradores com a finalidade de desenvolver novas competências e promoverem a aprendizagem organizacional.

Diante de uma visão holística e mudança no gerenciamento de pessoas principalmente da quebra do paradigma do chefe para o líder, o enfoque estratégico contemporâneo segundo Somaya e Williamson (2009) precisa estar além das manobras defensivas (tais como aumentar os benefícios dos funcionários) e das represálias (como exigir o cumprimento de cláusulas de não-concorrência que aparecem nos contratos de trabalho), as empresas desenvolvem ações relacionais com os colaboradores, oferecem descontos em produtos e outros benefícios com a finalidade de disseminar conhecimento e valorizar os talentos.

Em seguida, intensifica-se em cinco passos o processo estratégico no gerenciamento de pessoal focado na gestão do conhecimento corroborando com (CERTO; PETER,2005).

a) Análise do ambiente interno e externo;

b) Estabelecer a diretriz organizacional para o conhecimento;

c) Formulação da estratégia no gerenciamento de pessoas para a gestão do conhecimento;

d) Implementação da estratégia no gerenciamento de pessoas para a gestão do conhecimento;

e) Controle estratégico no gerenciamento de pessoal para o conhecimento. 


\section{a) Análise do ambiente interno e externo}

Pettigrew (1996) assevera a necessidade de analisar o processo de mudança a partir do contexto interno e externo à organização (porque mudar), do conteúdo da mudança (o que mudar) e do processo (como mudar), definido como uma abordagem contextualizada pela interação contínua entre os fatores. $O$ ambiente interno envolve a estrutura, a cultura organizacional e o contexto político da organização. No ambiente interno utiliza-se as seguintes ferramentas:

- Avaliação do clima organizacional;

- Avaliação de desempenho;

- Aplica-se o questionário de qualidade de vida no trabalho.

Sá (2006) defende que a gestão estratégica de pessoal tem a missão de contribuir para a performance da organização e que a chave para essa performance está exatamente nos multiplos comportamentos individuais e coletivos que partir de do ambiente interno, regem a atividade global das organizações. Alguns estudos empíricos realizados no Brasil por Sá e Lemoine (1998); Sá (1999, 2000); Medeiros, Albuquerque e Marques (2005) demonstram que a cultura e o clima da empresa influenciam, verdadeiramente, no comprometimento das pessoas em seus trabalhos e com a estratégia da organização.

Pettigrew (1996) define o ambiente externo pelo ambiente social, econômico, político e competitivo em que a organização está inserida atualmente. No ambiente externo observa-se:

- O mercado de recursos humanos;

- As empresas concorrentes do mesmo ramo de negócio.

Analisando o mercado de recursos humanos e as empresas concorrentes se tornam possível melhorar a política salarial, os benefícios, a higiene e a segurança no trabalho, principalmente desenvolver uma estrutura com liderança coletiva para a criação e germinação do conhecimento entre os membros.

Analisando o ambiente interno e externo empresarial é possível levantar os pontos fracos e pontos fortes e as ameaças e oportunidades. Com esse estudo o gerente de pessoas consegue mensurar e promover uma ação corretiva ou até mesmo manter pontos fortes e aproveitar oportunidades. "Saber identificar o correto ângulo de visão sobre as ações estratégicas na organização será o diferencial que garantirá a vantagem competitiva de nossas empresas em relação aos produtos e serviços” (BOOG, 2002). Essa análise é a base para as demais etapas.

\section{b) Estabelecer a diretriz organizacional para o conhecimento}


Após identificar os pontos fortes, pontos fracos, ameaças e oportunidades é necessário estabelecer metas com objetivos comuns. Geralmente as empresas apresentam missões divergentes das ações práticas. Nesse momento é de suma importância redirecionar as metas e tornar a missão verdadeira. Para esse segundo passo, no que tange o alinhamento estratégico, apresentar-se-á aspectos teóricos sobre Gestão do Conhecimento, Aprendizagem Organizacional e Vantagem Competitiva, Qualidade, Produtividade e Competitividade.

A empresa é composta de três níveis estratégico, tático e operacional que precisam ser coerentes com a missão e ter visão estratégica para acompanhar as mudanças.

O nível estratégico é composto de gerentes e diretores que precisam serem comprometidos à gestão do conhecimento.

O nível tático é composto de subgerentes e supervisores, esse geralmente tem um contato próximo dos colaboradores. Na implementação do gerenciamento de pessoal os subgerentes e os supervisores são extremamente importantes para o alcance dos objetivos. São eles que precisam ser multiplicadores sobre as novas formas de organizar o trabalho e disseminação do conhecimento, as principais características são: liderança, trabalho em equipe, motivação, ética, propulsor de aprendizagem organizacional e saber aceitar idéias dos colaboradores. "Um verdadeiro líder é aquele que é eleito pelos colaboradores e não aquele que é colocado no cargo". Por isso que é necessário primeiro abrir a vaga internamente para uma recolocação profissional, o plano de carreira precisa ser intensificado na estratégia empresarial.

O nível operacional é onde deve ser concentrado maior adesão e a liderança coletiva para a gestão do conhecimento, "o funcionário satisfeito e motivado que sabe o que faz processa produtos e serviços com qualidade e conseqüentemente reduz desperdícios e melhoram a margem de lucro empresarial" (GNIDARXIC, 2009).

Segundo Terra e Gordon (2002) o recurso conhecimento e as práticas para gerenciá-lo demandam profundo entendimento das práticas de trabalho, fontes de informação e aprendizado, avaliação de tecnologia pertinente e fatores motivacionais de diferentes grupos de indivíduos da organização. Desta forma exige que as organizações reconheçam que precisam realizar esforços mais focados em compreender como a variável conhecimento afeta seus processos, modelos de negócios e o desempenho de diferentes grupos de pessoas na empresa.

Segundo Gnidarxic (2009) as empresas que valorizam a gestão do conhecimento têm funcionários que sabem o que fazem, além de conhecerem os processos disseminam para outros membros. Como conseqüência reduz desperdícios. Marras (2000) corrobora e afirma, que a estratégia de recursos humanos tem uma ligação estreita com o planejamento organizacional, e necessita implementar em sua política a otimização e melhorias de qualidade e produtividade no trabalho, alavancado pelo desempenho humano. 


\section{Sobre Gestão do Conhecimento, Aprendizagem Organizacional e vantagem}

competitiva. A organização é um sistema de aprendizagem, os colaboradores aprendem como parte das suas atividades diárias, especialmente quando entram em interação com os outros e com o meio exterior. Os grupos aprendem quando os seus membros cooperam para atingir objetivos comuns. $\mathrm{O}$ sistema na sua globalidade aprende, ao obter feedback do ambiente, e antecipa mudanças posteriores.

O aprendizado individual tem um impacto significativo nas práticas de aprendizagem organizacional, pois a aprendizagem se inicia a partir dos indivíduos. A este respeito, enfatizam Nonaka e Takeuchi (1997): "Embora nós usemos o termo criação de conhecimento organizacional, a organização não pode criar conhecimento por si própria sem a iniciativa do indivíduo e a interação que acontece dentro do grupo". Conhecer a suas atividades pode ser fator determinante para melhorar a qualidade de produtos e serviços.

Nas organizações conhecer o aspecto sociotécnico dos funcionários é imprescindível no gerenciamento de pessoas principalmente para a disseminação do conhecimento. Nonaka e Takeuchi (1997) propõem um modelo de conversão de conhecimento com base na interação entre o conhecimento tácito e conhecimento explícito na Governança da empresa, pressupondo quatro formas de conversão, conforme ilustrado na Figura 1.

- Explícito, que se refere ao conhecimento transmissível em linguagem formal, sistemática, de forma objetiva;

- Tácito que possui uma qualidade pessoal, subjetiva, resultado de processamentos de informações e do aproveitamento de insights, intuições e em partes como habilidades técnicas, o tipo de destreza informal e de difícil especificação incorporado ao termo know-how.

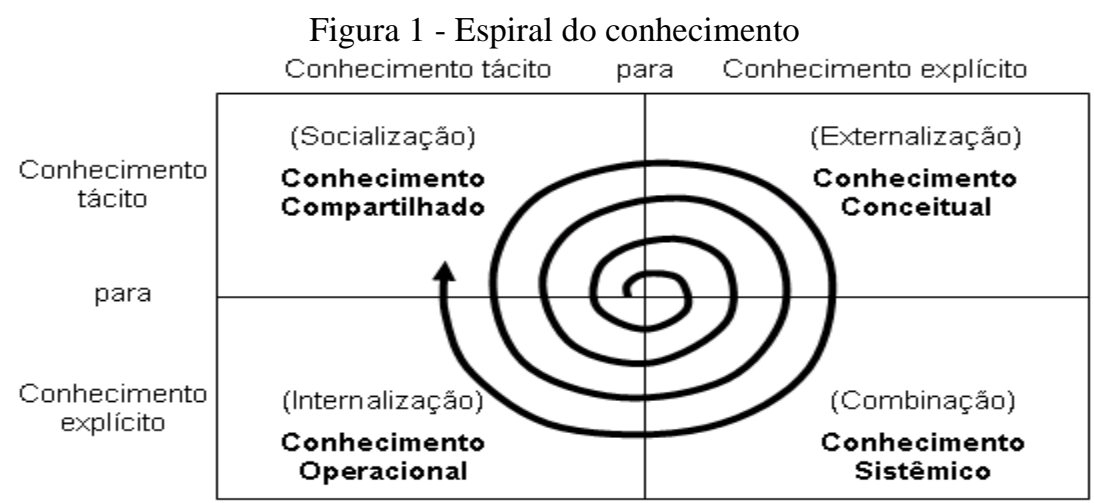

Fonte: Adaptado de (NONAKA;TAKEUCHI, 1997)

A socialização: é o processo pelo qual experiências são compartilhadas e o conhecimento tácito é socializado entre indivíduos.

Externalização: constitui o modo de conversão mais importante, porque permite a criação de novos e explícitos conceitos através dos conhecimentos tácitos que normalmente são de difícil 
verbalização.

Combinação: este processo se baseia na troca de informações explícitas e no paradigma da tecnologia de informação.

Internalização: através do "aprender fazendo". Quando a maioria compartilha do novo modelo mental, o conhecimento tácito passa a fazer parte da cultura organizacional e a cada internalização bem sucedida, o ciclo se reinicia, levando ao aperfeiçoamento ou à inovação.

Para a germinação e disseminação do conhecimento nas empresas é necessário desenvolver o gerenciamento de pessoas através do processo e estratégia de recursos humanos com valoração ao conhecimento tácito e explícito, no sentido de criar novas idéias e favorecer ao grupo artefatos realistas para tomadas de decisões com convicção da assertividade. A essas organizações da-se o nome de organizações que aprendem ou aprendizagem organizacional.

Segundo Garvin (1993) define a organização que aprende como "uma organização capacitada para criar, adquirir e transferir conhecimentos e modificar seu comportamento de modo a refletir novos conhecimentos e insights". Sendo assim, propõe cinco eixos para a aprendizagem organizacional:

- Resolução sistemática de problemas: este primeiro eixo privilegia a utilização de métodos científicos para diagnosticar problemas ao invés do tradicional o simples sentimento;

- Experimentação: consiste da procura sistemática de novos conhecimentos, onde a utilização do método científico é essencial;

- Aprendizagem com a experiência passada: está baseada na revisão sistemática das experiências conhecidas;

- Aprendizagem com o ambiente externo: a utilização de experiências vivenciadas por outras organizações também é um dos meios de se promover a aprendizagem;

- Difusão do conhecimento: decorre da transferência do conhecimento através de toda a organização como meio de capitalizá-lo. Pode ser promovida através de vários processos como, por exemplo, educação e treinamento, padronização, entre outras técnicas de difusão e formalização do conhecimento.

Em seguida, serão mencionadas algumas vantagens competitivas que as empresas adquirem quando implementam a estratégia no gerenciamento de pessoas, que valorizam no cerne da governança a gestão do conhecimento focada na aprendizagem organizacional.

Stewart (2002) relata que o conhecimento é a própria razão de ser da empresa. Não se consegue alcançar a vantagem competitiva com trabalho não qualificado, porque a vantagem competitiva duradoura deriva de algo exclusivo, ou pelo menos de difícil imitação: um tipo especial de conhecimento ou uma combinação singular de ativos do conhecimento e ativos físicos. 
Segundo Zacarelli (2000) as empresas adquirem vantagem competitiva pela existência de talentos especiais. Portanto é necessário valorizar as pessoas talentosas e evitar que elas sejam demitidas, porque elas irão levar consigo tal vantagem quando se desligam da empresa. Então é preciso haver métodos para retê-las como, a participação nos resultados da empresa. Essas pessoas enxergam situações futuras e oportunidades de mercado como empresas de propaganda, de investimento ou de desenvolvimento tecnológico.

Conforme Guaragna (2007), o aprendizado organizacional representa algo que é desejo de todas as organizações: um triplo benefício sinérgico do aprendizado organizacional conforme ilustrado na Figura 2 são eles:

- Benefício 1: constrói vantagem competitiva à organização - a medida que a organização está perceptiva ao ambiente, recebe e busca informações, gera conhecimento e os aplica, criando novas ou fortalecendo estratégias de negocio já existentes, de forma ágil e antecipatória aos seus concorrentes, ela constrói vantagem competitiva;

- Benefício 2: proporciona o desenvolvimento do ser humano - o aprendizado trabalha fortemente com a hierarquia de necessidades de Maslow (1943), inicialmente as pessoas buscam as necessidades básicas, isto é, um salário que dê para o sustento próprio e de seus dependentes, depois a almejam segurança e instabilidade, depois de satisfeita os dois níveis anteriores as pessoas perpetuam por um ambiente saudável com um ótimo convívio social na corporação e na vida familiar, satisfeita essas, os seres humanos buscam a estima, reconhecimento e valorização pelo serviço prestado e por fim as pessoas querem chegar ao topo da pirâmide se tornando alto realizadas profissionalmente;

- Benefício 3: cria cultura e competência diferenciadas para tratar de mudanças e incertezas - este benefício se estabelece à medida que as pessoas da organização adquirem uma dimensão elevada do aprendizado como forma de fazer frente às mudanças, indefinições e incertezas, para assim buscar a adaptabilidade necessária e extrair vantagem competitiva da mudança.

Figura 2 - Triplo benefício sinérgico do aprendizado organizacional através da implementação do processo e estratégia no gerenciamento de pessoal que valoriza a gestão do conhecimento 


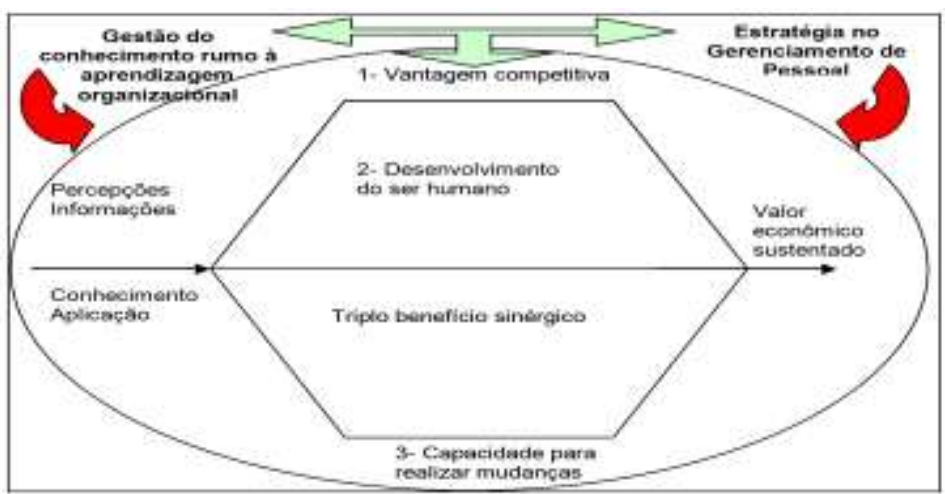

Fonte: Adaptado de Guaragna (2007)

Desta forma é possível concluir que a prática gerencial que se preocupar em germinar e disseminar o conhecimento através do fator humano, precisa em um primeiro momento conhecer o processo e a estratégia para o gerenciamento de pessoas.

O processo de Gestão do Conhecimento é uma ação prática desenvolvida por gerentes organizacionais que dão sentido de direção e de utilização para o ativo organizacional denominado conhecimento. Terra (2005) menciona "sete (7) dimensões que necessitam fazer parte da prática gerencial contemporânea":

- O papel da alta administração, revelando quais conhecimentos devem ser aprendidos pelos funcionários, além da definição de estratégias e desafios motivadores;

- Uma cultura organizacional voltada à inovação e ao aprendizado contínuo, comprometendo-se com resultados de longo prazo e com a maximização de recursos operacionais;

- Renovação das estruturas hierárquico-burocráticas de forma a desenvolver o trabalho de equipes multifuncionais, com autonomia para superar limites à inovação e aos novos conhecimentos;

- Melhores práticas de políticas de administração de recursos humanos para atrair e manter talentos e competências, criando sistemas de remuneração adequados;

- O avanço das tecnologias de informação que afetam os processos de geração, difusão e armazenamento de conhecimento nas empresas equilibrado com as necessidades de interação com as pessoas;

- Garantir a mensuração de resultados com uso de indicadores para as áreas significativas e em uma política de divulgação interna dessas informações;

- A necessidade crescente de engajamento em processos de aprendizado com o ambiente onde interagem as empresas, fazendo alianças com outras empresas e no relacionamento com clientes.

Portanto, através das sete dimensões apresentadas foi possível constatar que o único departamento citado sendo responsável para atrair talentos e disseminar a gestão por competências é 
a administração de recursos humanos, corroborando com os objetivos desse artigo.

Sobre Qualidade, Produtividade e Competitividade. Para a empresa ser competitiva, precisa oferecer seus produtos ou serviços com a qualidade esperada pelos clientes e com preços aceitáveis pelo mercado. Para que seus preços sejam competitivos, a empresa deve ter custos compatíveis, o que exige produtividade no uso dos recursos de que dispõe. Analisando como se processa o relacionamento entre qualidade e produtividade, chegou-se à Figura 3, que ilustra com detalhes a importante interação entre qualidade e produtividade que resulta no aumento da competitividade organizacional. Ulric (1998) relata que a gestão estratégica de recursos humanos pode criar valor para a empresa no que tange o envolvimento das pessoas nos processos, podendo prover recursos. Pettigrew (1996) relata que o processo é analisado pelas ações e interações entre as várias áreas envolvidas na mudança e no futuro da organização. Em específico a esse estudo, a área de produção.

Figura 3 - Qualidade e produtividade como bases para a competitividade

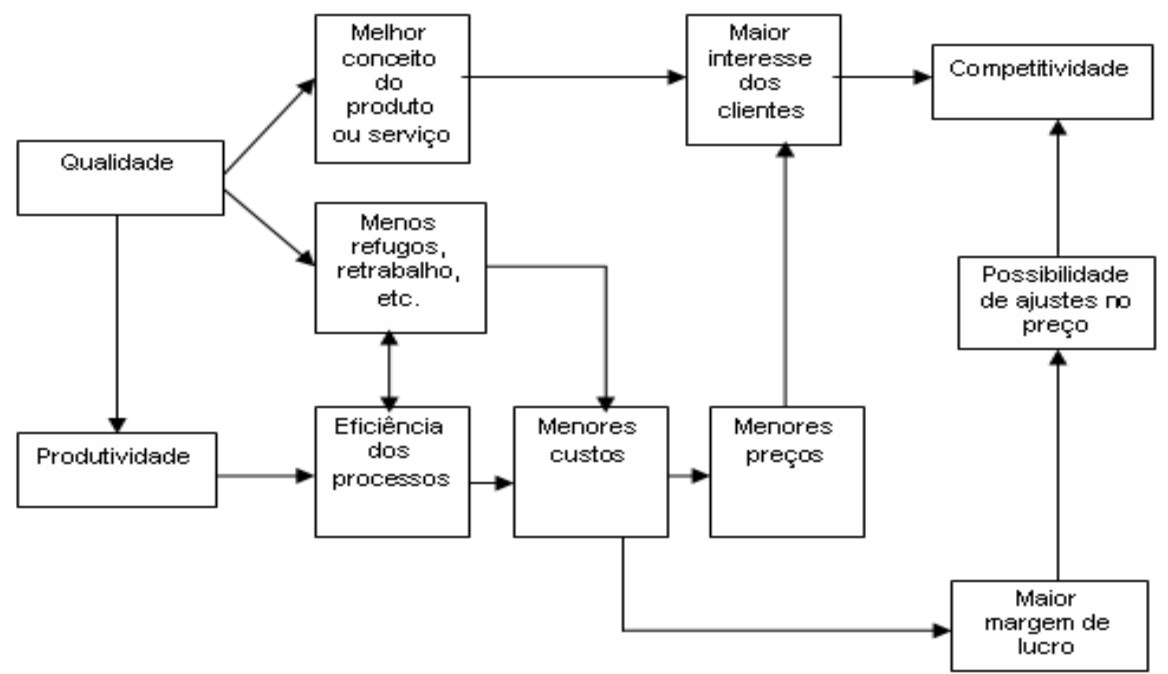

Fonte: Autores (2011)

Segundo Costa Neto (2007), diversas conceituações podem ser encontradas para competitividade, mas, em essência, uma empresa é competitiva se tem, conserva ou amplia a fatia do mercado para seus produtos ou serviços, e se está apta a enfrentar a atuação dos concorrentes.

Existem diversas visões buscando esclarecer como se tornar competitivo. A Figura 4 sintetiza o importante relacionamento entre a Qualidade e Produtividade como elementos básicos para se chegar à competitividade.

Figura 4 - Qualidade, produtividade e competitividade 


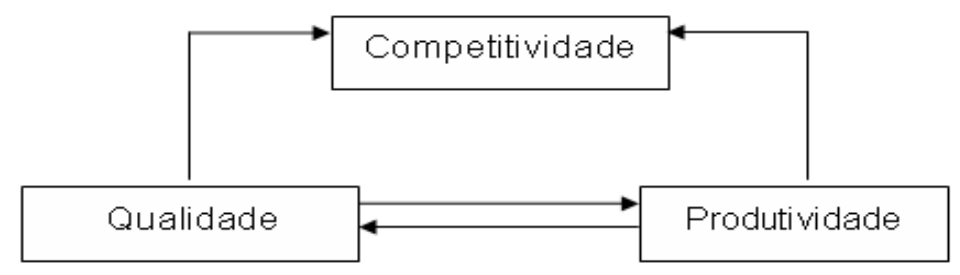

Fonte: Costa Neto (2007)

Contador (1998) afirma que a produtividade pode ser definida como a capacidade de produzir, partindo-se de uma certa quantidade de recursos, ou ainda como o estado em que se dá a produção. A produtividade é medida pela relação entre os resultados efetivos da produção e os recursos produtivos aplicados a ela (produção/recursos), tais como peças/hora-máquina, toneladas produzidas/homem-hora, quilogramas fundidos/quilowatt-hora, toneladas de soja/hectare (onde ano está implícito por corresponder à safra), carros produzidos/funcionário-ano, toneladas de aço/homem-ano, etc. Pode-se medi-la para cada recurso isoladamente, o que propicia a avaliação do comportamento e do desempenho individual. Não obstante, também é possível medir a produtividade considerando a totalidade dos recursos utilizados para gerar uma determinada produção (bens ou serviços).

Após estabelecer a diretriz organizacional é impresindível formular a estratégia.

\section{c) Formulação da estratégia no gerenciamento de pessoas para a gestão do conhecimento}

Segundo Pereira e Lissoni (2008) a formulação da estratégia está intimimamente vinculado às definições do conceito de estratégia. A forma como as estratégias surgem não é idêntica em todas as organizações, resulta de uma conjugação de fatores externos e de condições internas que configuram cada situação em particular. Costa (2007) reforça, a formulação de uma estratégia não é uma ciência exata, nessa área há muito engenho de arte, ou seja, invenção, criação, experimentação, ajustes, enfim um processo de melhorias e de experimentação contínuas.

Mintzberg et.al., (2000) relatam que o processo de formualação de estratégia é um misto de jogos de poder em busca de vantagem competitiva, socialização coletiva, aprendizado, planejamento, mas cada um deve ser encontrado dentro do seu tempo e de seu próprio contexto.

Certo e Peter (2005) relatam que formular estratégias implica determinar cursos de ação apropriados para alcançar objetivos. Isso inclui atividades como análise, planejamento e seleção de estratégias que aumentam as chances da organização atingir suas metas. Para isso, sugere-se uma análise das questões críticas a fim de fornecer a estrutura necessária para o estudo da situação atual da organização e propicia a formulação de estratégia eficazes, sendo assim, é necessário responder a quatro questões básicas: 1) Quais são o(s) propósito(s) e o(s) objetivo(s) da organização? A resposta dessa questão informa aos administradores onde a organização quer chegar, evitando inconsistência 
entre missão, objetivos e estratégias; 2) Para onde a organização está indo no momento? A resposta revela se a organização está atingindo suas metas; 3) Que fatores ambientais críticos a organização enfrenta atualmente? Essa questão objetiva refletir sobre a análise interna e externa; 4) O que pode ser feito para que os objetivos organizacionais sejam alcançados de forma mais efetiva no futuro? A resposta a essa pergunta resulta na formulação de uma estratégia. Portanto por meio das quatro perguntas, os administradores poderão formular estratégias organizacionais apropriadas, mas isso só irá ocorrer se houver a compreensão sobre aonde a organização quer chegar, para onde ela está indo e qual o ambiente ela opera.

\section{d) Implementação da estratégia no gerenciamento de pessoas para a gestão do conhecimento}

A implementação da estratégia no gerenciamento de pessoal para a gestão do conhecimento, é o momento de colocar em prática a metodologia proposta na formulação.

Implementar uma estratégia não é uma tarefa fácil, é preciso verificar o impacto à mudança, precisa verificar a aceitação das pessoas frente a tais mudanças principalmente junto com as metas colocar a remuneração especial e participação nos lucros para incentivar a motivação dos colaboradores. Kanter, Stein e Jick (1992) relatam que, entre as dificuldades de fazer a mudança acontecer, está o excessivo otimismo, o declínio da excitação após período inicial, o insuficiente reconhecimento do valor e benefícios da burocracia tradicional e a carência de capacidades para gerenciar a mudança. Ruas (2001) complementa que o principal dilema da gestão da mudança é redimensionar as competências individuais da organização, mas especificamente das competências gerenciais, a fim de aportar as competências organizacionais os elementos fundamentais do processo de mudança. Segundo o autor, os gestores precisam superar a visão dominante acerca de pensar as mudanças no nível superficial (técnicas, normas e regras) e ter capacidade de mudar a si próprio e internalizar a noção sobre a importância do seu papel nos processos de mudança.

Implementar uma nova diretriz é semelhante a uma "via de mão dupla", não adianta forçar metas que não motivam as pessoas à execução das mesmas, o ideal é que as pessoas consigam alcançá-las e conquistem retornos (motivação, satisfação dos colaboradores, aprendizagem organizacional e como conseqüência lucratividade para a empresa).

É importante também, antes de implementar a estratégia no gerenciamento de pessoas conhecerem a cultura organizacional. Segundo Certo e Peter (2005) por um lado toda organização (enquanto sinônimo de grupo) carrega consigo traços culturais próprios que a definem, portanto, tem uma cultura, por outro, é comum observar que são poucas as organizações que externam essa cultura, aceitando-a formalmente, defendendo-a e difundindo-a a todos os seus empregados. 
Mas, esse é o enfoque do alinhamento que deverá ser dado as atividades e aos programas de recursos humanos, priorizando-se a criação de competências e de características culturais necessárias à implementação de um processo de mudança, reforçando-se os pontos positivos identificados e eliminando-se aspectos negativos ou disfunções organizacionais que possam comprometer os objetivos da empresa (BOOG, 2002).

Segundo Fleury (1996) o processo de mudança não pode ser descolado da cultura organizacional, pela forte influência que essa exerce ao longo do processo, ela adverte, que quanto mais forte for a cultura organizacional, mais profunda será essa influência, sendo assim, a cultura organizacional tanto age como elemento de consenso, como oculta e instrumentaliza as relações de dominação, tornando a mudança de padrões culturais bem mais complexa, em função da significativa resistência em vários segmentos da organização.

Torna-se necessário utilizar os seguintes passos conforme (CERTO; PETER, 2005):

- Levantar, conhecer e diagnosticar a cultura da empresa;

- Frizar os valores e costumes nos grupos a fim integrar os traços culturais;

- Treinar pessoas para entronizar os elementos culturais e se tornarem multiplicadores;

- Avaliar constantemente o ambiente interno e externo para ações corretivas, muitas vezes para reforçar a cultura organizacional.

Os lideres coletivos exercem um papel fundamental na disseminação da cultura corporativa, necessitando de atuação exemplar. A abordagem utilizada para implementar uma estratégia é a colaborativa, porque é possível integrar todos os colaboradores em prol de objetivos comuns. Segundo Certo e Peter (2005), na abordagem colaborativa, o gerente de pessoal é responsável pela estratégia e reúne a equipe de colaboradores a fim de explorar idéias e tentar formular e implementar a estratégia, através dessa abordagem propicia a captura de informações de todos os níveis organizacionais e incentiva a participação individual e grupal aumentando a intensificação do comprometimento.

Albuquerque (2002) corrobora alertando que o engajamento das pessoas no processo de mudança é imprescindível para a implementação da estratégia organizacional. $\mathrm{O}$ autor relata que os principais fatores culminam na participação das pessoas no processo, seu aprendizado, sua conscientização e seu comprometimento com os intentos da organização.

$\mathrm{O}$ ultimo aspecto que precisa de atenção após identificar o impacto à mudança, ter analisado a cultura organizacional e saber qual o tipo de abordagem que irá ser utilizada é preciso antes da implementação preparar a organização frente aos tópicos citados a respeito do impacto à mudança, se a implementação será uma estratégia radical (muda radicalmente o cotidiano das pessoas) ou limitada (apenas pequenas mudanças, muitas vezes apenas modificar numericamente as metas já estabelecidas).

Conclui-se que antes de implementar a estratégia do gerenciamento de pessoal é 
necessário desenvolver um estudo detalhado com a finalidade de reduzir incertezas e aumentar as chances de sucesso empresarial com a nova retórica traçada.

\section{e) Controle estratégico no gerenciamento de pessoal para o conhecimento.}

Após implementar a nova meta na organização é de suma importância exercer o controle. Essencialmente porque se concentra na monitoração e avaliação do processo como um todo.

O controle estratégico no gerenciamento de pessoal requer a medição no desempenho organizacional através de auditorias com metas organizacionais qualitativas e quantitativas. Segundo Boog (2002), é necessário aprender a identificar e medir resultados que, de fato, possam adicionar valor à organização, como por exemplo, específico a esse trabalho mensurar o volume de peças produzidas sem defeito.

É preciso saber implementar o controle estratégico de maneira colaborativa. Como já mencionado, a implementação de metas por objetivos que valoriza o esforço humano através de remuneração estratégica e satisfação dos colaboradores traz lucratividade para a organização.

$\mathrm{Na}$ atualidade não se usa mais o controle centralizado (eu mando e você obedece), as pessoas não gostam de serem chefiadas de maneira comandada e sim através da gestão participativa e colaborativa com metas por objetivos de uma via de mão dupla.

\section{Estudo de caso}

Este estudo de caso foi realizado em uma empresa de autopeças, que tem como principais produtos de fabricação os elementos de suspensão de automóveis e caminhões. A empresa em questão vinha apresentando excesso de retrabalho e sucata quando comparada com empresas similares do grupo, este desperdício influenciava na produtividade, na qualidade dos produtos e na competitividade da empresa. Portanto o problema consistia em pesquisar as causas para a não qualidade.

Os dados sobre a quantidade de sucata e a produtividade foram reunidos utilizando como base as informações obtidas em reuniões operacionais realizadas mensalmente na empresa pesquisada. Os dados apresentados despertaram a necessidade de uma análise mais profunda sobre a causa, ou causas para o efeito da não qualidade. Observando os relatórios de não conformidade verifica-se que a falha decorrente do fator humano era reincidente, portanto uma análise mais abrangente deu origem as açoes descritas abaixo:

Implantação da estratégia de pessoal voltada para disseminação do conhecimento em cinco passos: 
a) Análise do ambiente interno e externo;

b) Estabelecer a diretriz organizacional para o conhecimento;

c) Formulação da estratégia no gerenciamento de pessoas para a gestão do conhecimento;

d) Implementação da estratégia no gerenciamento de pessoas para a gestão do conhecimento;

e) Controle estratégico no gerenciamento de pessoal para o conhecimento; mostrar por meio de indicadores de desempenho: i. o levantamento das falhas por motivo de falta de conhecimento; ii. A evolução do aprendizado; iii. o índice PPM (partes por milhão) e iv. a produtividade após melhorias na qualidade.

\subsection{Metodologia e caracterização da pesquisa}

A metodologia utilizada foi a pesquisa-ação que tem como definição e características:

A pesquisa-ação é um tipo de pesquisa social com base empírica que é concebida e realizada em estreita associação com uma ação ou resolução de um problema coletivo e no qual os pesquisadores e os participantes representativos da situação ou do problema estão envolvidos de modo cooperativo ou participativo (THIOLLENT, 2007).

As características do método de pesquisa-ação são:

a) A pesquisa-ação só é qualificada como metodologia de pesquisa se houver realmente uma ação em curso por parte de pessoas ou grupos atuando no problema em observação;

b) $\mathrm{O}$ pesquisador deve desempenhar papel ativo no equacionamento dos problemas encontrados, bem como no acompanhamento e na avaliação das ações desencadeadas;

c) A relação entre pesquisador e pesquisados deve ser de natureza participativa

d) É preciso que haja domínio teórico, pelo pesquisador, do conhecimento temático abordado para que possa orientar a pesquisa.

Gil (2002) relata que a categoria da pesquisa exploratória desenvolve:

a) levantamento bibliográfico;

b) entrevistas com pessoas que tiveram experiências práticas com o problema pesquisado;

c) análise de exemplos que estimulem a compreensão. Em relação à natureza metodológica, Oliveira (1999) enfatiza que existem duas tipologias básicas: a quantitativa e a qualitativa.

O método do estudo de caso, segundo Fachin (2003), é caracterizado por ser um estudo in locus, leva-se em consideração, principalmente a compreensão, como um todo, do assunto investigado através da entrevista a fim de apresentar uma análise descritiva.

\subsection{Justificativa da metodologia de pesquisa}


Quanto à natureza, a presente pesquisa é aplicada, pois trata de problemas específicos de uma indústria de autopeças possuidora do sistema de gestão da qualidade e que utiliza a norma ISO/ TS 16949 como forma de realizar melhorias contínuas. A empresa também se preocupa com a necessidade de criar, desenvolver e disseminar o conhecimento de seus produtos e processos com o apoio da estratégia no gerenciamento de pessoal.

No que se refere à abordagem do problema, trata-se de uma pesquisa qualitativa, já que parte de focos e interesses amplos, que vão se definindo à medida que o estudo prossegue. Envolve a obtenção de dados descritivos sobre processos interativos pelo contato direto do pesquisador com a situação estudada, na tentativa de compreender os fenômenos segundo a perspectiva dos sujeitos, ou seja, dos participantes da situação estudada (GODOY, 1995). Alguns dados podem ser quantificados, porém a análise propriamente dita é qualitativa (STRAUSS; CORBIN, 1990).

No que tange ao objetivo da pesquisa, podemos classificá-la como uma pesquisa exploratória, que proporciona maior compressão do fenômeno que está sendo investigado. Geralmente, a pesquisa exploratória é a primeira etapa de uma investigação maior que abrangerá outros níveis e questionamentos. O aspecto a ser analisado é o conhecimento dos principais processos de fabricação por parte dos colaboradores. O presente trabalho tem como objetivo verificar o conhecimento que eles detêm, caracterizando a pesquisa exploratória.

O pesquisador acompanha as auditorias, participa da definição da possível causa para os problemas da não qualidade e ministra os treinamentos sobre os processos de produção. Já os pesquisados participam de várias ações com vistas ao atendimento dos requisitos da norma ISO/ TS 16949, como entendimento e aplicabilidade da política de qualidade, treinamentos e participação em auditorias internas.

Esse fato demonstra a caracterização do método de pesquisa como pesquisa-ação, devido à postura participante do pesquisador e ao envolvimento de terceiros no processo produtivo sob análise.

\subsection{Análise do ambiente interno e externo da empresa em estudo}

Pettigrew (1996) sugere que a questão (Porque mudar?), deve ser respondida analisando-se o contexto interno e externo da organização em estudo.

No atual mercado competitivo é possível afirmar que somente as empresas que buscam a excelência irão sobreviver. Identificar as Forças e Fraquezas da empresa, extrapolando então para as Oportunidades e Ameaças externas.

A ferramenta utilizada foi a Análise S.W.O.T. (ou análise F.O.F.A. em português) é uma ferramenta estrutural utilizada na análise do ambiente interno, para a formulação de estratégias. Permite-se identificar as Forças e Fraquezas da empresa, extrapolando então Oportunidades e 
Ameaças externas para a mesma.

Quanto a ferramenta utilizada não há registos precisos sobre a origem desse tipo de análise, segundo Públio (2008) a análise SWOT foi criada por dois professores da Harvard Business School: Kenneth Andrews e Roland Christensen. Por outro lado, Tarapanoff (2001) indica que a ideia da análise SWOT já era utilizada há mais de três mil anos quando cita em uma epígrafe um conselho de Sun Tzu: "Concentre-se nos pontos fortes, reconheça as fraquezas, agarre as oportunidades e proteja-se contra as ameaças ". A Quadro 2, 3 e 4 demonstram esta análise realizada na empresa pesquisada.

Quadro 2: Pontos fortes e fracos da empresa

\begin{tabular}{|l|l|}
\hline \multicolumn{1}{|c|}{ PONTOS FORTES } & \multicolumn{1}{c|}{ PONTOS FRACOS } \\
\hline - Marca Forte no Mercado de Reposição & -Tempo de resposta para nos Desenvolvimento de \\
- Flexibilidade Produtiva/Mix & Protótipos \\
- Tecnologia & - Utilização de 100\% da capacidade Produzida \\
- Capacidade Produção / 100\% Produção & - Preço reposição \\
- Entrega Sequenciada & - Equipamentos antigos \\
- Conhecimento e experiência & - Aprendizado \\
- Produção de produto único Centro de Distribuição & - Perda de pessoal/ reter \\
& -Área Útil \\
\hline
\end{tabular}

Fonte: Empresa pesquisada (2011)

Quadro 3:Ameaças de mercado

\begin{tabular}{|c|c|c|c|}
\hline Evento / Tendência & Quais são as ameaças & Probabilidade & Impacto/Efeito \\
\hline -Mudança de legislação & $\begin{array}{l}\text { Abertura de mercado } \\
\text { Regulamentação veicular } \\
\text { Regulamentação ABNT } \\
\text { Inspeção veicular }\end{array}$ & $\begin{array}{l}\mathrm{A} \\
\mathrm{A} \\
\mathrm{A} \\
\mathrm{M}\end{array}$ & $\begin{array}{l}\text { Cliente importar } \\
\text { Perda de volume } \\
\text { Niveladores concorrentes }\end{array}$ \\
\hline $\begin{array}{l}\text { - Desenvolvimento } \\
\text { tecnológico dos } \\
\text { concorrentes }\end{array}$ & $\begin{array}{l}\text { Suspensão progressiva } \\
\text { Material Tubular } \\
\text { Processo a frio } \\
\text { Capacitação de pessoal dos concorrentes } \\
\text { Capacitação tecnológica dos concorrentes }\end{array}$ & $\begin{array}{l}\text { M } \\
\text { M } \\
\text { A } \\
\text { A } \\
\text { A }\end{array}$ & $\begin{array}{l}\text { Falta de capacidade } \\
\text { Perda de volume } \\
\text { Perda de participação } \\
\text { Perda de novos negócios } \\
\text { Perda de novos negócios }\end{array}$ \\
\hline - Colaboradores & $\begin{array}{l}\text { Perda de colaboradores chave } \\
\text { p/concorrência/mercado }\end{array}$ & A & $\begin{array}{l}\text { Transferência/perda de } \\
\text { k.how/estratégia }\end{array}$ \\
\hline - Concorrentes & $\begin{array}{l}\text { Cliente virar fabricante/concorrentes } \\
\text { Alianças globais } \\
\text { Concorrente ser adquirida por novo grupo }\end{array}$ & $\begin{array}{l}\mathrm{M} \\
\mathrm{A} \\
\mathrm{M}\end{array}$ & Perda de negócio \\
\hline - Mercado & Desaceleração econômica & $\mathrm{M}$ & Perda de volume \\
\hline
\end{tabular}

Probabilidade: $\mathrm{A}=$ Alta $\mathrm{B}=$ Baixa $\quad \mathrm{M}=$ Média

Fonte: Empresa pesquisada (2011)

Quadro 4: Oportunidades

\begin{tabular}{|l|l|l|l|}
\hline \multicolumn{1}{|c|}{ Evento / tendência } & Qual são as oportunidades específicas? & Probabilidade & \multicolumn{1}{c|}{ Impacto/efeito } \\
\hline - Mudança de & Abertura de Mercado & A & Importar matéria-prima \\
Legislação & Regulamentação veicular & A & Aumento de volume $10 \%$ \\
& Suspensão progressiva & A & $\begin{array}{l}\text { Eliminação parcial de } 5 \% \\
\text { dos concorrentes. }\end{array}$ \\
\hline
\end{tabular}




\begin{tabular}{|l|l|l|l|}
\hline $\begin{array}{l}\text { - Desenvolvimento } \\
\text { Tecnológico do grupo }\end{array}$ & $\begin{array}{l}\text { Suspensão progressiva } \\
\text { Material Tubular } \\
\text { Processo a frio } \\
\text { Capacitação de pessoal } \\
\text { Capacitação tecnológica dos concorrentes }\end{array}$ & A & $\begin{array}{l}\text { Aumento de participação } \\
\text { Imagem da organização }\end{array}$ \\
\hline - Colaboradores & Trazer colaboradores da concorrência & B & Aquisição de know-how \\
\hline - Concorrentes & $\begin{array}{l}\text { Alianças Globais } \\
\text { Compra de um concorrente } \\
\text { Associação c/concorrente ou cliente }\end{array}$ & $\begin{array}{l}\text { A } \\
\text { M }\end{array}$ & Aquisição de Negócios \\
\hline - Mercado & Aceleração da economia & A & Aumento de Volume \\
\hline - Fornecedores & Aquisição de fornecedores & B & $\begin{array}{l}\text { Eliminação de } \\
\text { dependência }\end{array}$ \\
\hline
\end{tabular}

Probabilidade: $\mathrm{A}=$ Alta $\mathrm{B}=$ Baixa $\quad \mathrm{M}=$ Média

Fonte: Empresa pesquisada (2011)

Pettigrew (1996) sugere que a questão (O que mudar?), deve ser respondida analisando-se as tecnologias, mão-de-obra, processos, produtos e serviços, posicionamento geográfico e cultura organizacional. No caso em estudo, os Quadros representados acima demonstram aspectos relevantes quanto ao aprendizado e a capacitação de seus colaboradores, o Quadro 2 destaca que o aprendizado dos colaboradores é um dos pontos fraco da organização, o Quadro 3 aponta como uma ameaça a capacitação de pessoal dos concorrentes e conclusivamente o Quadro 4 destaca como oportunidade de melhoria a capacitação do pessoal, portanto, buscou-se em um primeiro momento implementar a estratégia no gerenciamento de pessoal para a gestão do conhecimento a fim de disseminar conhecimentos dos processos e produtos e serviços para os colaboradores, sendo assim visa o comprometimento e a sinergia dos mesmos.

\subsection{Diretriz organizacional para a gestão do conhecimento}

A diretriz organizacional para a gestão do conhecimento da empresa pesquisada esta fundamentada em aspectos como: sua visão, missão e objetivos da empresa em relação ao conhecimento. Estes aspectos são descritos abaixo:

Visão em relação ao conhecimento: Ter e manter colaboradores capacitados e motivados diante dos conhecimentos necessários à execução de seus processos e consequentemente dos processos vitais para empresa ser competitiva.

Missão em relação ao conhecimento: identificar, criar, organizar, disseminar, avaliar, mensurar, reter e proteger o conhecimento.

Objetivos em relação ao conhecimento: através do conhecimento dos processos manter uma política de qualidade que possa reduzir os índices de retrabalho e sucata de forma a influenciar positivamente os índices de qualidade e de produtividade, garantindo a competitividade da organização. 
Pettigrew (1996) sugere a questão (Como mudar?), é analisado pelas ações, reações e interações entre as várias áreas envolvidas na mudança e no futuro da organização. Os passos para a mudança serão abordados no item 3.5. Formulação da estratégia no gerenciamento de pessoas para a gestão do conhecimento.

\subsection{Formulação da estratégia no gerenciamento de pessoas para a gestão do conhecimento:}

um exemplo de aplicação em uma empresa de fabricação de molas

A realização prática das ações preconizadas teoricamente pelo modelo considerado ocorreu, após diversas reuniões de discussão e planejamento de soluções, mediante a proposição de um método a ser utilizado no processo em consideração, constituído das seguintes etapas:

-Utilizar a ferramenta diagrama de causa e efeito para verificar entre as principais causas de cada problema a real causa;

-Classificar as reais causas ocorridas durante ano utilizando o gráfico de Pareto;

-Criar gráficos mensais para acompanhar índices de peças com problemas de qualidade ocasionados por falta de conhecimento PPM (peças por milhão) antes da realização de algum treinamento.

O índice de PPM é representado pela divisão da quantidade de peças defeituosas pelo número de peças fabricadas; o valor obtido deve ser multiplicado por 1 milhão, ou seja:

$$
\text { PPM }=\left(\frac{\text { № de peças defeituosas }}{\text { № de peças fabricadas }}\right) \times 1.000 .000
$$

- Aplicar avaliação de conhecimento dos processos para os operadores antes de realizar treinamento (avaliação teórica);

- Treinar operadores nas principais etapas do processo, demonstrando a interação entre elas e destacando a importância de sua operação do contexto final;

- Medir o aprendizado, aplicando a mesma avaliação inicial e comparar resultados entre avaliações;

- Acompanhar mensalmente os problemas de qualidade ocorridos por falta de conhecimento após realização do treinamento;

- Comparar os resultados em PPM após realização dos treinamentos;

- Tomar ações de melhoria no treinamento caso necessário;

- Validar método caso houver diminuição dos índices de PPM (peças por milhão) ou diminuição de não conformidades ocorridas por falta de conhecimento, comparando os resultados entre os gráficos de PPM antes e após aprendizado; 
- Verificar os resultados de produtividade e lucratividade da organização, comparando determinados períodos.

A empresa pesquisada, entende que "os funcionários que sabem o que fazem, apresentam motivação para o trabalho, cooperação e participação nas tarefas envolvidas e a maior conseqüência é a redução de desperdícios" (GNIDARXIC, 2009). Portanto buscou-se incentivar a cooperação e participação dos colaboradores através da liderança coletiva, sendo implementada no processo estratégico para o gerenciamento de pessoal a fim de disseminação do conhecimento e vantagem competitiva empresarial e principalmente sobrevivência em período de crise Figura 5 da seguinte maneira:

- contratar pessoas certas e gerar novas capacidades internas;

- aplicar a avaliação do clima organizacional, a avaliação de desempenho e a análise da qualidade de vida no trabalho. Esse sub-processo de aplicação tem o objetivo de tornar o ambiente de trabalho saudável para os colaboradores de maneira propícia a germinação do conhecimento, para isso deve ser promovido de forma organizada;

- atribuir benefícios, salário especial, higiene e segurança no trabalho para o objetivo de armazenar e promover a manutenção de talentos, o capital intelectual precisa ser armazenado com valorização, porque são fontes de idéias importantes para o desenvolvimento organizacional;

- desenvolver pessoas, significa valorizá-las, atribuir oportunidades a quem merece, as pessoas ficam satisfeitas e motivadas quando atribuem idéias criativas e essas são colocadas em prática, ou seja, as criatividades são utilizadas e disseminação por toda a governança do conhecimento;

- implementar um sistema de informação integrado de maneira que possa armazenar dados e seja uma ferramenta para o controle e tomada de decisão;

- definir o processo de gerenciamento de pessoal como um processo estratégico contínuo e interativo que visa manter a organização em um conjunto apropriado e integrado a seu ambiente. Para que ocorra a implementação correta do gerenciamento de pessoal é necessário intensificar no planejamento estratégico os objetivos organizacionais com a disseminação do conhecimento. Desta forma foi apresentado um modelo estratégico específico para a área de recursos humanos, no qual este será mencionado os tópicos mais importantes: 
Figura 5 - Processo estratégico de gerenciamento de pessoal na disseminação do conhecimento

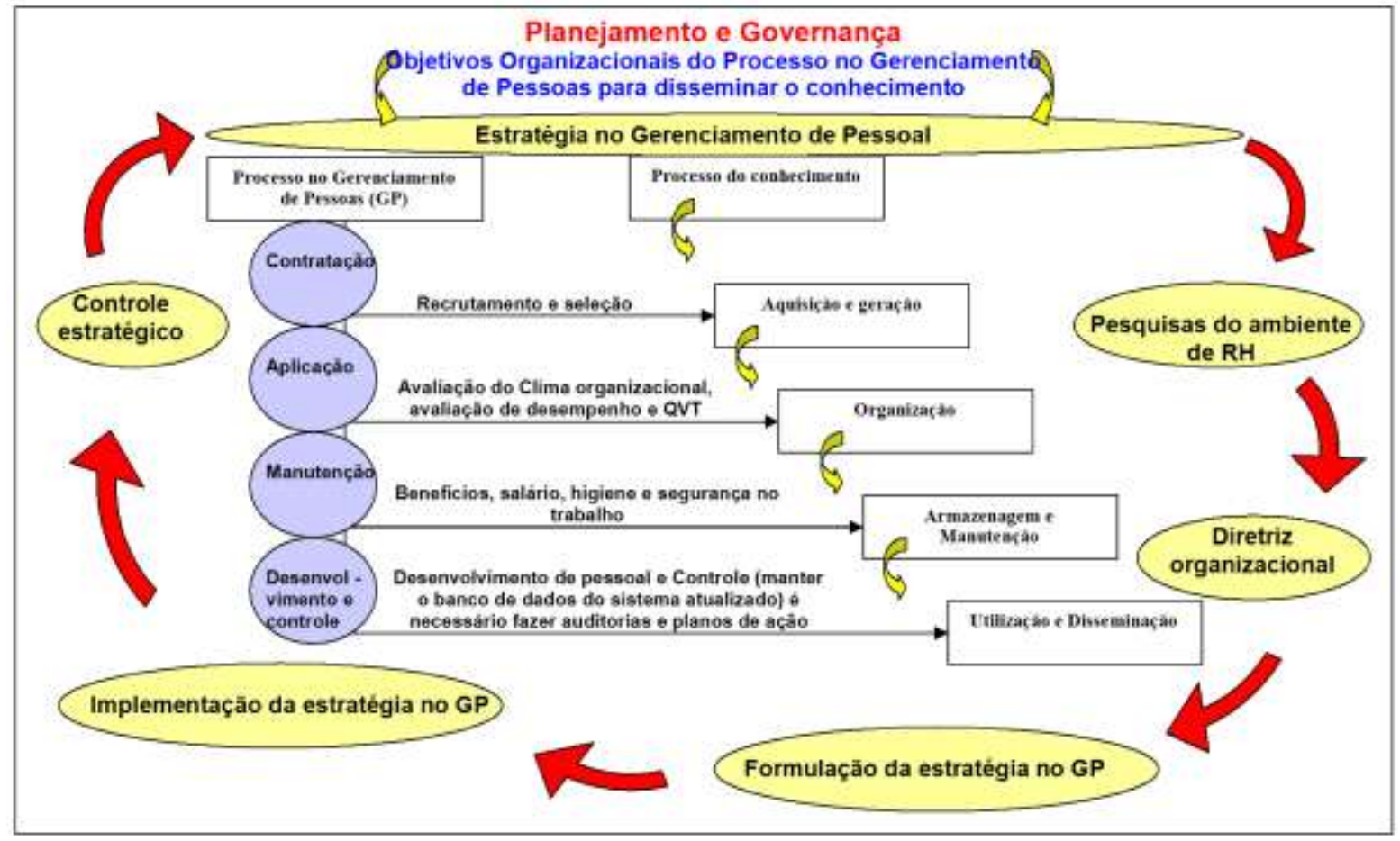

Fonte: Autores (2011)

Depois de formulado a estratégia, essa etapa envolveu a apresentação do estudo de caso, a metologia e as características da pesquisa e sua justificativa, sinergicamente em prol do desenvolvimento estratégico para o gerencimento de pessoal e disseminação do conhecimento, a continuidade é a implementação da estratégia.

\subsection{Resultados da implementação da estratégia no gerenciamento de pessoas para a gestão do conhecimento}

\subsubsection{Resultados com o foco na aprendizagem organizacional}

O Gráfico 1 demonstra que as principais causas para os problemas da não qualidade são os métodos e a mão de obra representa $71 \%$ dos problemas ocasionados pela falta de conhecimento dos processos.

Gráfico 1 - Porcentual das causas nos processos produtivos

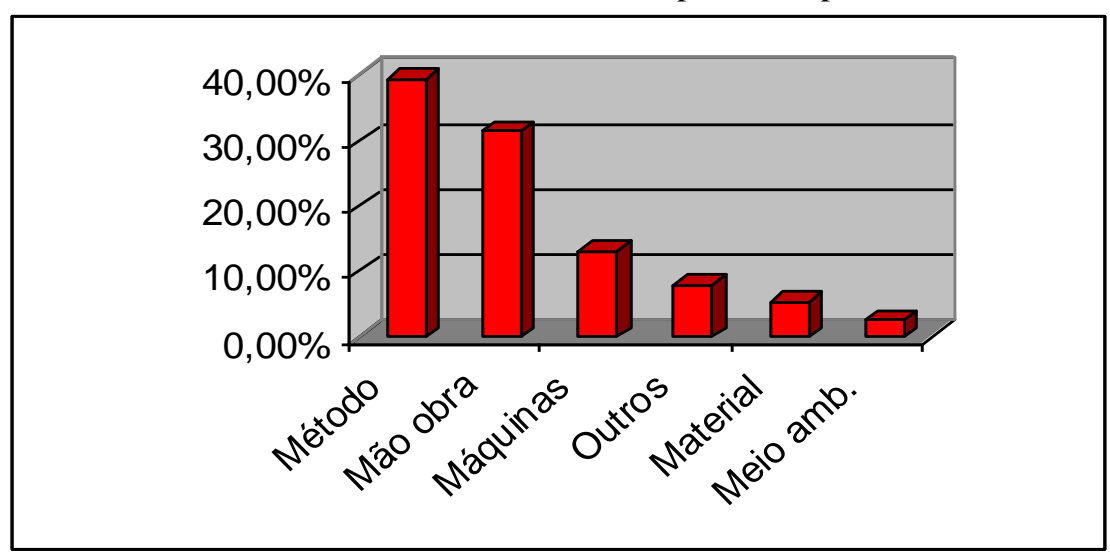

Fonte: Autores (2011) 
O Gráfico 2 demonstra a quantidade de não qualidade, representada pelo índice PPM (peças por milhão).

Gráfico 2 - Mostra as ocorrências de defeitos em PPM no ano de 2007

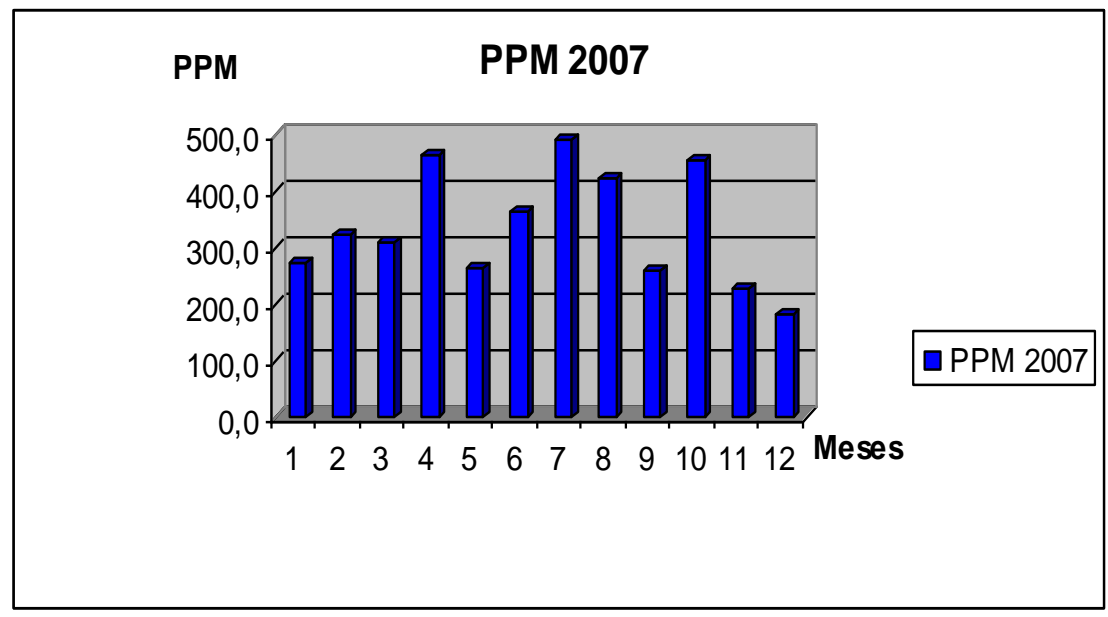

Fonte: Autores (2011)

Na sequiência foi aplicada avaliação de conhecimento dos processos aos operadores, antes de realizar treinamento. Foi então aplicado o treinamento nas principais etapas de processo, de forma que várias turmas foram treinadas (40 horas).

O Gráfico 3 mostra a evolução do aprendizado decorrente desse processo de treinamento, passando a média das avaliações de 6,49 antes do treinamento para 8,55 depois deste.

Gráfico 3 -Evolução do aprendizado

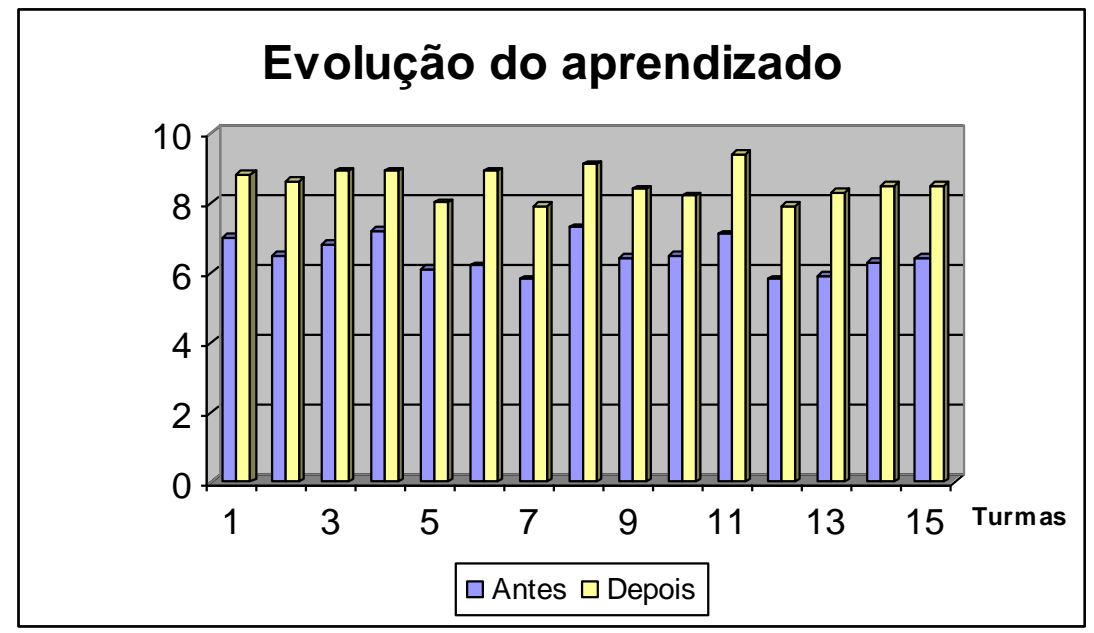

Fonte: Autores (2011)

O resultado referente às partes defeituosas em PPM é apresentado no Gráfico 4, comparativo a 2007, mostrando portanto, a diminuição de 82,3 \% no índice PPM. 
Gráfico 4 - Comparativo entre PPM 2007 e 2008

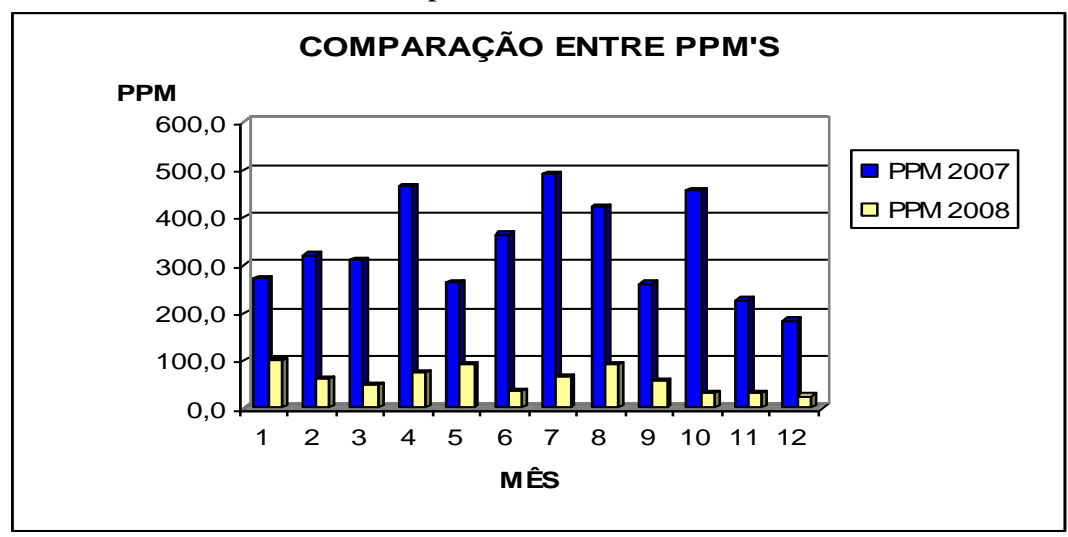

Fonte: Autores (2011)

\subsubsection{Resultados com o foco na produtividade}

Outro resultado relevante da pesquisa é sobre o ganho de produtividade, para isso multiplica-se a quantidade de mão-de-obra com a quantidade de horas trabalhadas no mês, ou seja, em 2007 com resultado de 131.560 (homens x horas) e em 2008 igual a 129.030 (homens x horas). Cabe ressaltar que a quantidade de horas e dias trabalhados nos respectivos anos foram padronizadas, já a mão-de-obra diminuiu, no ano de 2007 com a média de 260 colaboradores e no ano de 2008 com a média de 255, ou seja, diminuição de aproximadamente $2 \%$ resultado este obtido através da diminuição do retrabalho entre os anos. O resultados são representados no Gráfico 5.

Gráfico 5 - Comparativo de número de homens. horas

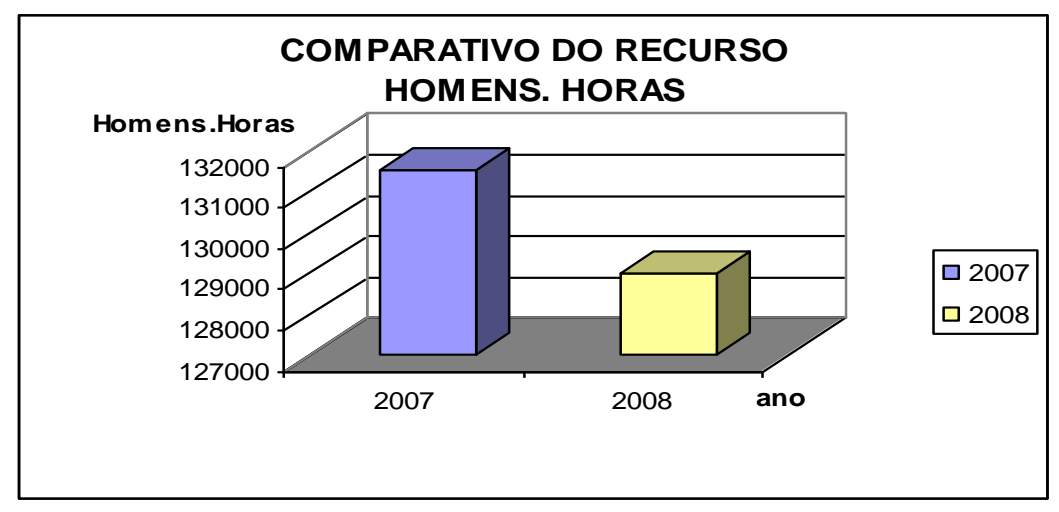

Fonte: Autores (2011)

Como a produtividade refere-se ao maior ou menor aproveitamento dos recursos no processo de produção, portanto diz respeito a quanto se pode produzir partindo de uma quantidade de recursos. O Gráfico 6 demonstra a comparação dos resultados de produtividade entre os anos de 2007 e 2008. A unidade utilizada para medição de produtividade foi o número de peças produzidas dividida pelo número de homens multiplicado por horas (Produtividade = peças/H.h). 


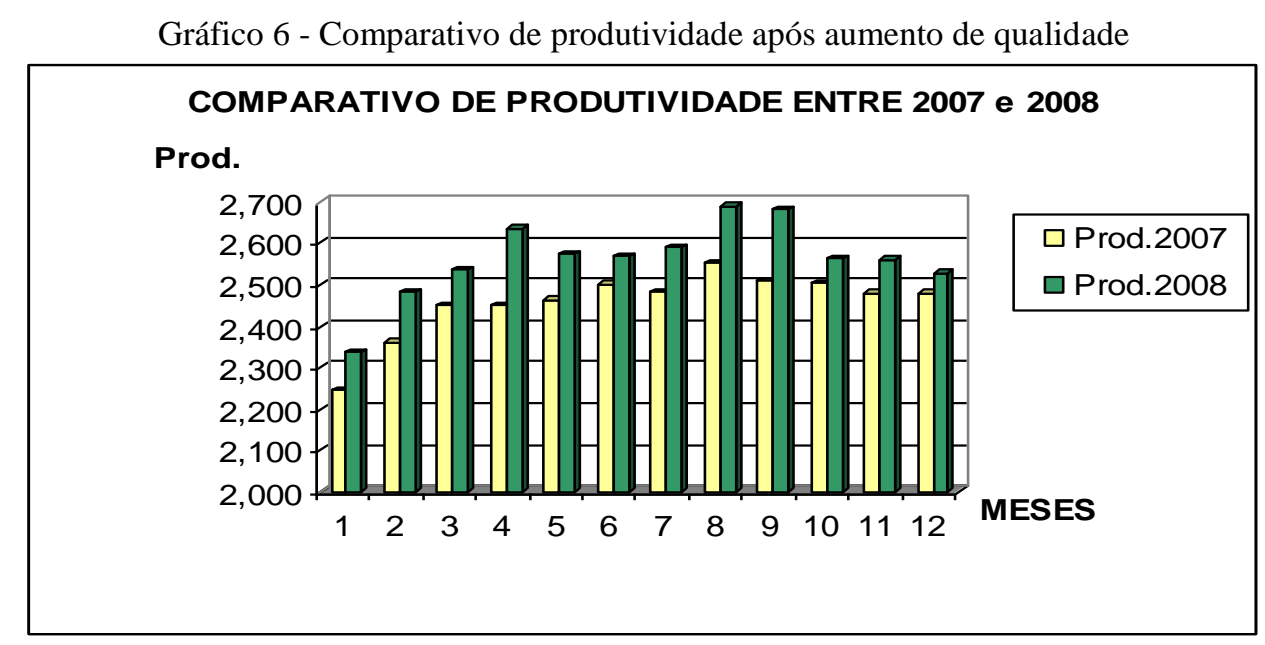

Fonte: Autores (2011)

Os cálculos apresentados nesta pesquisa são baseados no custo unitário médio, pois se trata de produtos semelhantes. Com a melhora na qualidade dos produtos a empresa diminuiu os índices de sucata e retrabalho, portanto, foi possível diminuir os recursos e conseqüentemente melhorar a produtividade aumentando o lucro da organização em 5,3\% Conforme demonstrado na Tabela 4.

Tabela 4- Custos após diminuição dos recursos

\begin{tabular}{lcc}
\hline \multicolumn{1}{c}{ Variáveis para o cálculo } & $\mathbf{2 0 0 7}$ & $\mathbf{2 0 0 8}$ \\
\hline Custo fixo & $\mathrm{R} \$ 1.800 .700,00$ & $\mathrm{R} \$ 1.800 .700,00$ \\
Custo variável médio por peça & $\mathrm{R} \$ 23,44$ & $\mathrm{R} \$ 22,91$ \\
Custo Fixo médio por peça & $\mathrm{R} \$ 6,03$ & $\mathrm{R} \$ 6,03$ \\
Custo total por peça & $\mathrm{R} \$ 29,47$ & $\mathrm{R} \$ 28,94$ \\
Valor de venda médio & $\mathrm{R} \$ 51,00$ & $\mathrm{R} \$ 51,00$ \\
Quantidade média produzida & 323.075 & 330.500 \\
Lucro Total no mês & $\mathbf{R} \mathbf{7 . 1 0 3 . 0 0 8 , 0 0}$ & $\mathbf{R} \mathbf{7 . 4 8 1 . 6 8 3 , 0 0}$ \\
\hline Autores $(2011)$ & &
\end{tabular}

\subsection{Controle estratégico no gerenciamento de pessoal para o conhecimento}

Uma organização pode ter diversos indicadores de desempenho, cada um deles é fator de comparação interno ou externo. A empresa pesquisada utilizou os seguintes indicadores: a) levantamento das falhas por motivo de falta de conhecimento, mensurava $71 \%$ do total; b) evolução do aprendizado, antes dos treinamentos a nota média dos conhecimentos era de 6,49 após o treinamento específico aumentou para 8,55; c) índice PPM (partes por milhão), que demonstrou uma queda de $82,3 \%$ nos problemas ocasionados pela falta de conhecimento; d) produtividade após melhorias na qualidade, mostrou-se uma redução de $2 \%$ no retrabalho, também apresentou-se um aumento no lucro da empresa em 5,3\%. Portanto, por meio dos resultados, a implementação do gerenciamento de pessoal voltada para a disseminação do conhecimento é uma forma de gestão que pode aumentar a competitividade da organização. 


\section{Conclusão}

A quebra do paradigma do ditador e comandante para o disseminador de conhecimento e compromissado com a organização veio à tona principalmente pelo ritmo da mudança tem se acelerado tão rapidamente. Em momentos de crise é imprescindível utilizar uma liderança coletiva. O perfil dos líderes que conseguem vencer as dificuldades não pode pensar apenas em seus objetivos individuais, precisam intensificar no pensamento dos liderados seus traços, para assim unificar forças em busca do sucesso empresarial.

Os lideres coletivos estabelecem uma missão estratégica inspiradora que busca a satisfação dos funcionários com compromisso à aprendizagem organizacional.

Marras (2000); Boog (2002); Terra (2005) corroboram afirmando que o departamento de recursos humanos precisa ser estratégico para um gerenciamento de pessoas, sendo um propulsor de aprendizagem organizacional. O estudo de caso evidencia que a implementação do gerenciamento de pessoal voltada para a disseminação do conhecimento pode gerar produtos com melhor qualidade.

O processo de implementação estratégica no gerenciamento de pessoas se iniciou com a análise do ambiente interno e externo. No ambiente interno avaliou-se o clima organizacional, o desempenho e a qualidade de vida no trabalho. No ambiente externo observou-se o mercado de recursos humano focados na empresa do mesmo ramo de negócio a fim de levantar dados sobre as empresas concorrentes: política salarial, os benefícios, a higiene e a segurança no trabalho, principalmente desenvolver uma estrutura com liderança coletiva para a criação e germinação do conhecimento entre os membros. Analisando o ambiente interno e externo empresarial é possível levantar os pontos fracos e pontos fortes e as ameaças e oportunidades. Com esse estudo o gerente de pessoas consegue mensurar e promover uma ação corretiva ou até mesmo manter pontos fortes e aproveitar oportunidades. "Saber identificar o correto ângulo de visão sobre as ações estratégicas na organização será o diferencial que garantirá a vantagem competitiva de nossas empresas em relação aos produtos e serviços" (BOOG, 2002). Essa análise é a base para as demais etapas.

O próximo passo foi estabelecer a diretriz organizacional para o conhecimento, nesse mostra-se por meio de revisão bibliográfica a importância da Gestão do Conhecimento e da Aprendizagem Organizacional para a vantagem competitiva, resultando em melhorias de qualidade e produtividade na empresa pesquisada.

Em seguida formula-se a estratégia no gerenciamento de pessoal para a gestão do conhecimento em estudo de caso, desenvolve-se uma proposta de modelo para o gerenciamento de pessoal e disseminação do conhecimento.

Após a formulação da estratégia é estudado com critérios o impacto da mudança, a cultura organizacional, o tipo de abordagem gerencial a ser utilizado (comandado ou colaborativo), assim a 
organização estará apta para a implementação estratégica no gerenciamento de pessoal, na análise dos dados, concebida na implementação do projeto, percebeu-se que $71 \%$ das falhas ocorridas era por falta de conhecimento, que após a implementação dos treinamentos específicos houve uma evolução no aprendizado, antes a nota era 6,49 e depois 8,55, também houve diminuição em $82,3 \%$ no indicador PPM (peças por milhão), a redução em 2\% dos recursos utilizados e um incremento de 5,33 \% no lucro da organização são indicadores que podem melhorar quando existem colaboradores que conhecem e disseminam o conhecimento.

Com o processo implementado é necessário controlar o desempenho, para isso desenvolveu-se quatro indicadores de desempenho que subsidiaram a análise quantitativa: a) levantamento das falhas por motivo de falta de conhecimento; b) evolução do aprendizado; c) índice PPM (partes por milhão) e d) produtividade após melhorias na qualidade.

A contribuição deste trabalho esta focada no despertar para a importância da estratégia no gerenciamento de pessoas através da gestão do conhecimento, destacando o fator humano como um diferencial. A capacidade de aprender mais rapidamente do que os concorrentes talvez seja a principal vantagem competitiva da atualidade.

\begin{abstract}
The purpose of this work is to present a competitively by implementing personnel management focused on the dissemination of knowledge. The methodology of the research is exploratory source characterized by qualitative and quantitative way through action research method. Will presented a case study of applied in a company in which the problem autoparts consisted in researching the cause for not quality, which led to the verification of the influence of knowledge in product quality. Searching back information about: collective leadership for knowledge management highlighted the importance of the leader as a set more rich and diverse skills to disseminate knowledge among the led, organizational learning and competitive advantage, knowledge management as a determining factor to acquire, generate, organize, store and disseminate knowledge. The study aims to evaluate through indicators: i. the lifting of failures by reason of lack of knowledge, ii. If there were developments in learning after implementation specific trainings, iii. the index of PPM (parts per million), iv. productivity after improvements in quality and knowledge regarding reduction of rework and increase revenues. Reaches the conclusion that the strategic deployment in personnel management focused on dissemination of knowledge can modify other indicators of performance of the Organization and the ability to learn faster than competitors as the main competitive advantage when so many economic uncertainties.
\end{abstract}

Key-words: collective leadership; strategy in personnel management; knowledge management.

\title{
Referências
}

ALBUQUERQUE, L.G. O papel estratégico de recursos humanos. 1987. Tese (Livre Docencia) - Departamento de Administração da Faculdade de Economia, Administração e Contabilidade, Universidade de São Paulo, São Paulo, 1987.

ALBUQUERQUE, L.G. A estratégia de pessoas. IN: FLEURY, M.T.L (Org) As pessoas na organização. São Paulo: Gente, 2002. 
ANTHONY, W. P; PERREWÉ, P. L; KACMAR, M. K. Strategic human resource management. Flórida: Harcourt Brace Publisher \& CO, 1996.

BOOG, et al. Manual de gestão de pessoas e equipes: estratégias e tendências. São Paulo: Editora Gente, 2002.

CERTO, S. C.; PETER, J. P. Administração estratégica: planejamento e implantação da estratégia. São Paulo: Pearson Education do Brasil, 2005.

COSTA, E. A. Gestão estratégica da empresa que temos para a empresa que queremos. São Paulo: Saraiva, 2007.

FACHIN, O. Fundamentos de metodologia. 4. ed. São Paulo: Saraiva, 2005.

FLEURY, M. T. L. O desvendar a cultura de uma organização: uma discussão metodológica. IN: FLEURY, M.T.L.; FISCHER, R.M. (Org). Cultura e poder nas organizações. 2. ed. São Paulo: Atlas, 1996.

FRANÇA, A. C. L. Comportamento organizacional: conceitos e práticas. São Paulo: Saraiva, 2006.

GARVIN, D. Buildng a learning organization. Harvard Business Review. p. 78 - 91, jul/ago.1993.

GIL, A. Como elaborar projetos de pesquisa. 4. ed. São Paulo: Atlas, 2002.

GNIDARXIC P.J. A Qualidade e o Conhecimento como fatores para Melhoria de Processos. 2009. Dissertação (Mestrado em Engenharia de Produção) - Instituto de Ciências Exatas e Tecnológicas, Universidade Paulista, 2009.

GODOY, A. S. Pesquisa qualitativa: tipos fundamentais. RAE, v. 35, n.3, p.20-29, 1995.

GUARAGNA,E. Desmistificando o aprendizado organizacional. São Paulo: Qualitymark, 2007.

KANTER, R. M.; STEIN, R. A.; JICK, T. D. The challenge of organizational change: how companies experience it and leaders guide it. The Free Press, Maxwell Macmillan Inc, 1992.

LARSON, R.C.; STREHLE, G. P. Edu-tech: what's a president to do.IN: GOODMAN, P.S. (Org). Technology enhanced learning: opportunities for change. London: Lawrence Errlbaum Associates, 2002.

MASLOW, A. H. A theory of human motivation. Psychological Review, 1943.

MEDEIROS, C. A. F.; ALBUQUERQUE, L. A.; MARQUES, G. M. Comprometimento Organizacional: um estudo de suas relações com características organizacionais e desempenho nas empresas hoteleiras. In: ENCONTRO ANUAL DA ASSOCIAÇÃO NACIONAL DE PÓS-GRADUAÇÃO E PESQUISA EM ADMINISTRAÇÃO, 29, 2005 , Brasília. Anais... Brasília, 2005.

MINTZBERG, H. et.al. Safári de estratégias: um roteiro pela selva do planejamento estratégico. Porto Alegre: Brookman, 2000.

NONAKA, I.; TAKEUCHI, H. Criação de conhecimento na empresa: como as empresas japonesas geram a dinâmica da inovação. 13.ed. Rio de Janeiro: Elsevier. 1997.

OLIVEIRA, S. L. Tratado de metodologia científica. São Paulo: Editora Pioneira, 1999.

PÚBLIO, M. A. Como planejar e executar uma campanha de propaganda. São Paulo: Atlas, 2008.

PEREIRA, M.F; LISSONI, J. Processos estratégicos: uma contribuição a partir do jazz. In: ANGELONI, M.T; MUSSI, C.C. (Org). Estratégias - formulação, implementação e avaliação, o desafio das organizações contemporâneas. São Paulo: Editora Saraiva, 2008.

PETTIGREW, A. M. A cultura das organizacões é administrável. In: FLEURY, M.T.L.; FISCHER, R.M. (Org). Cultura e poder nas organizações. São Paulo, Atlas, 1996.

RAO, S. A forma que a liderança terá. HSM Management: Rio de Janeiro, p. 76-82, jan/ fev. 2009.

RUAS, R. Desenvolvimento de competencias gerenciais e contribuição da aprendizagem organizacional. In: FLEURY, O.J.R (Org). Gestão estratégica do conhecimento: integrando aprendizagem, conhecimento e competência. São Paulo, 
Atlas, 2001.

SÁ, M.A.D.; LEMOINE, C. O estilo de liderança como fator de comprometimento na empresa. In: ENCONTRO NACIONAL DA ASSOCIAÇÃO NACIONAL DE PÓS GRADUAÇÃO E PESQUISA EM ADMINISTRAÇÃO, 1998, Foz do Iguaçu. Anais... Rio de Janeiro, 1998.

SÁ, M.A.D. Em matéria de comprometimento da empresa, são os valores individuais que contam. In: ENCONTRO NACIONAL DA ASSOCIAÇÃO NACIONAL DE PÓS GRADUAÇÃO E PESQUISA EM ADMINISTRAÇÃO,1999, Foz do Iguaçu. Anais... Foz do Iguaçu, 1999.

SÁ, M.A.D. Cultura de empregado como estratégia de empresa. In: ENCONTRO NACIONAL DA ASSOCIAÇÃO NACIONAL DE PÓS GRADUAÇÃO E PESQUISA EM ADMINISTRAÇÃO, 2000, Florianópolis. Anais... Florianópolis, 2000.

SÁ, M.A.D. Espelho não tem duas faces: um estudo entre o clima e cultura organizacional na UFPB. In: ENCONTRO NACIONAL DA ASSOCIAÇÃO NACIONAL DE PÓS GRADUAÇÃO E PESQUISA EM ADMINISTRAÇÃO, 2006, Salvador. Anais... Salvador, 2006.

SCHARMER, O. A teoria U e a proposta para a crise. HSM Management: Rio de Janeiro, p. 95-98, jan/fev. 2009.

SOMAYA, D.; WILLIAMSON, I. Guerra pelo talento contrário. HSM Management: Rio de Janeiro, p. 110-116, jan/ fev. 2009.

STEWART, T.A. Riqueza do conhecimento: o capital intelectual e a organização do século XXI. Rio de Janeiro, Campus, 2002.

STRAUSS, A.; CORBIN, J. Basics of qualitative research: grounded theory procedures and techniques. London: Sage Publications, 1990.

TARAPANOFF, K. Inteligência organizacional e competitiva. Brasília: Editora UNB, 2001.

TERRA, J.C.C. Gestão do Conhecimento : o grande desafio empresarial. Rio de Janeiro: Elsevier, 2005.

TERRA, J.C.C.; GORDON, C. Portais Corporativos: a evolução da gestão do conhecimento. São Paulo: Negócios Editora, 2002.

THIOLLENT, M. Metodologia da pesquisação. 15. ed. Cortez: São Paulo, 2007.

URIC, D. Os campeões de recursos humanos: inovando para obter os melhores resultados. São Paulo: Futura, 1998.

ZACARELLI, S. B. Estratégia e sucesso nas empresas. São Paulo: Saraiva, 2000.

\section{Dados dos autores:}

Nome completo: Geraldo Cardoso de Oliveira Neto

Filiação institucional: Universidade Nove de Julho (UNINOVE)

Departamento: Ciências Gerenciais

Função ou cargo ocupado: Coordenador e Professor de Ensino Superior

Endereço completo para correspondência: Rua José Cristy, 01, Bairro: Flórida, Cidade: EmbuGuaçu, Estado: São Paulo, País: Brasil e CEP: 06900-000.

Telefones para contato: 011-76127859

e-mail: geraldo.prod@ig.com.br 
Nome completo: Paulo José Gnidarxic

Filiação institucional: Universidade Nove de Julho (UNINOVE)

Departamento: Ciências Gerenciais

Função ou cargo ocupado: Professor de Ensino Superior

Endereço completo para correspondência: Rua Das Orquídeas, 90, Vila Helena, Santo André CEP: 09176-050, São Paulo.

Telefones para contato: 011-72427273

e-mail:paulo.j@uninove.br

Nome completo: Pedro Luiz de Oliveira Costa Neto

Filiação institucional: Universidade Paulista (UNIP)

Departamento: Engenharia de Produção

Função ou cargo ocupado: Professor de Ensino Mestrado e Doutorado

Telefones para contato: 011-91081233

e-mail:politileia@uol.com.br

Enviado em: 19/11/2010

Aprovado em: 16/12/2011 